\title{
O CUSTO DE ARRECADAÇÃO DE TRIBUTOS FEDERAIS*
}

\author{
THE COST OF FEDERAL TAXATION
}

\author{
ALDO V. BERTOLUCCI \\ Doutor em Controladoria e Contabilidade \\ pela Faculdade de Economia, Administração e Contabilidade \\ da Universidade de São Paulo - Campus Capital \\ E-mail: aldo.bertolucci@ppeinvex.com.br \\ DIOGO TOLEDO DO NASCIMENTO \\ Professor Doutor do Departamento de Contabilidade e Atuária \\ da Faculdade de Economia, Administração e Contabilidade \\ da Universidade de São Paulo - Campus Capital \\ E-mail: dtoledo@usp.br
}

\section{RESUMO}

Há um aspecto da tributação que não tem despertado a atenção dos pesquisadores e que é representado pelos custos operacionais tributários que são os custos com que Fisco e Contribuintes têm que arcar para que os tributos sejam pagos e também sejam cumpridas todas as obrigações acessórias da tributação. Já se verificou que os custos dos contribuintes - os custos de conformidade à tributação - correspondem a 0,75\% do PIB na média das companhias abertas e pode alcançar 5,82\% do PIB nas companhias abertas com receita bruta anual de até R\$ 100 milhões por ano. Enfoca-se, neste trabalho, outro custo operacional tributário que é o custo que a União tem para administrar tributos federais. São apresentados os custos de vários países e o resultado da pesquisa no Brasil que busca refletir quais são os custos dos órgãos da União relacionados à arrecadação de tributos federais. A pesquisa de campo demonstrou que o Poder Público tem, ainda, grandes dificuldades com o controle adequado de suas contas, tendo-se constatado falta de uniformidade e de transparência. Outro aspecto verificado é o fato de ser o Poder Público parte em mais de $90 \%$ dos processos em andamento nos tribunais federais, sendo, portanto, o grande causador da lentidão da Justiça Federal. Os custos de arrecadação apurados correspondem a 1,35\% da receita e a 0,36\% do PIB e, somados aos custos de conformidade, alcançam 1,11\% do PIB, correspondendo a R $\$ 16,8$ bilhões. Ao final do trabalho, são apresentadas propostas para o aperfeiçoamento do sistema e redução de seus custos.

Palavras-chave: Administração tributária; Arrecadação; Tributação.

\section{ABSTRACT}

There is an aspect in taxation which has not called the attention of researchers: its operational cost, that is, the costs the fiscal administration and taxpayers incur to have taxes paid and to comply with the bureaucratic aspects of taxation. It has already been calculated that the compliance costs of taxation correspond to $0.75 \%$ of GDP in average listed companies and can be as high as 5.82\% of GDP in companies with less than $R \$ 100$ million in sales per year. This paper deals with another operational cost of taxation: the costs the Brazilian Federal Administration has to administer federal taxation. We present a survey of the costs in other countries and in Brazil, attempting to picture the taxation costs incurred by different federal administrative entities. The survey shows that the public administration faces great difficulties to adequately control its accounts and that there is lack of uniformity and transparency. Another aspect is the fact that the Government is involved in more than $90 \%$ of judicial processes, being the main responsible for delays in federal courts. The administrative costs of taxation correspond to $1.35 \%$ of tax revenues and $0.36 \%$ of GDP. The total of operating costs of taxation correspond to $1.11 \%$ of GDP or $R \$ 16.8$ billion. Finally, we propose measures to improve the system and reduce its costs.

Keywords: Fiscal administration; Tax Revenues; Taxation. 


\section{INTRODUC̣ÃO}

Este trabalho teve como objetivo levantar os custos da administração de tributos no Brasil. Um dos principais temas de discussão no campo tributário tem sido o peso da arrecadação sobre o PIB, que cresceu de $27,29 \%$ em 1997 para $35,68 \%$ em 2003. Porém, esses percentuais só levam em consideração uma parte dos custos totais apresentados na Figura I $\bullet$. Mesmo sem conseguir estimar os custos de distorção - que se pode supor sejam elevados em virtude da evolução desordenada do sistema tributário do Brasil, cujo principal objetivo tem sido arrecadatório - buscou-se estimar os custos operacionais tributários e incluí-los no ônus tributário. Sandford (1989, p. 20) define custos de distorção como os custos decorrentes de mudanças nos tributos e que, ao alterar preços de produtos e de fatores da produção, mudam padrões de comportamento econômico agindo como desincentivos ao esforço e à iniciativa ou mudando tendências do consumo ou da produção.

Esse tema não tem sido tratado com a profundidade desejada em muitos países do mundo e não há estudos no Brasil a respeito. Falta metodologia de trabalho e não há padrões estabelecidos para a mensuração desses custos. Esse fato decorre, em parte, da diversidade das organizações das administrações tributárias nos vários países, mas também da pouca divulgação que vem sendo dada aos estudos para a racionalização dessas atividades.

Vito Tanzi, diretor do Departamento de Assuntos Fiscais do Fundo Monetário Internacional, escreve, no prefácio de Bird e Jantscher (1992, p. iii - iv), que sempre foi fonte de surpresa para ele o fato de que tantos escrevam sobre tributação, mas tão poucos escrevam sobre administração tributária, assumindo, implicitamente, que a administração de sistemas tributários é um problema trivial. Porém, continua ele, tributação é a arte do possível e um sistema tributário que não seja administrável não vale grande coisa. Um sistema, teoricamente perfeito, pode se tornar um mau sistema se a intenção expressa pela lei for distorcida pela prática.

De fato, a bibliografia sobre tributação e sobre reforma tributária é extremamente rica, mas relativamente poucos autores têm dedicado atenção aos custos operacionais tributários e, mais especificamente, aos custos da Administração Tributária.

No Brasil, as autoridades tributárias não divulgam suas informações a respeito de custos de administração tributária e os outros órgãos envolvidos - no Executivo e no Judiciário - não têm controles e informações adequadas para o levantamento desses custos.

Este trabalho tem o objetivo de definir uma metodologia de cálculo e uma visão do campo de aplicação que permita a outros pesquisadores evoluir com este estudo e dotar a sociedade de meios de controle de recursos públicos que viabilizem sua alocação mais eficaz. O escopo restringiuse aos custos da Administração Tributária Federal com a arrecadação de tributos federais. Essa decisão decorreu do fato de que, na Federação, há 27 Estados e mais de 5.500 Municípios, todos com competência tributária tornando impraticável o levantamento de todos esses custos.

Inicialmente, apresenta-se uma visão panorâmica das administrações tributárias de outros países, mostrando suas políticas de transparência e suas dificuldades de apuração. Em seguida, são evidenciados os resultados de pesquisas sobre os custos administrativos dos seguintes entes da União, em suas atividades relativas à tributação:

l) No Executivo

a) Secretaria da Receita Federal

b) Procuradoria Geral da Fazenda Nacional

c) Instituto Nacional da Seguridade Social

2) No Legislativo

Outra premissa aqui utilizada é a de que, no Legislativo, a atividade relacionada à tributação é relativamente inexpressiva em relação ao seu volume total de trabalho, não sendo, portanto, computada.

3) No Judiciário

Todos os níveis dos tribunais federais, sejam os regionais, bem como os tribunais superiores, o Superior Tribunal de Justiça (STJ) e o Supremo Tribunal Federal (STF)

\section{CUSTOS OPERACIONAIS TRIBUTÁRIOS}

A evolução dos estudos dos Custos de Conformidade é bastante recente, foi descrita por Bertolucci (2003) e pode ser vista através de três Congressos realizados de 1988 até 2000 e que são:

a) Rio de Janeiro em 1988 pela International Fiscal Association (IFAC);

b) Oxford em 1994:

c) Sydney em 2000.

Os participantes tiveram um núcleo central composto pelo Professor Cedric Sandford e mais alguns estudiosos do assunto. Esse grupo foi ampliado sucessivamente a cada Congresso. Verificou-se uma evolução sensível entre o pri- meiro Congresso e o de Sydney porque, no primeiro, foram apresentados poucos trabalhos, com referências bibliográficas muito limitadas e formas de pesquisa embrionárias. Poucos participantes tinham idéia clara do que se estava discutindo e isso pode ser visto pelos anais do Congresso (1 989). No Congresso de Sydney (200 I), foram apresentados 23 trabalhos, extensa bibliografia e formas sofisticadas de pesquisa. Mais importante, muitas das pesquisas estavam em andamento, ou seja, muito se estava fazendo de novo nesse campo.

Bertolucci (2003, p. 139) apresenta quadro com os custos de conformidade levantados junto às companhias abertas associadas da ABRASCA - Associação Brasileira das 


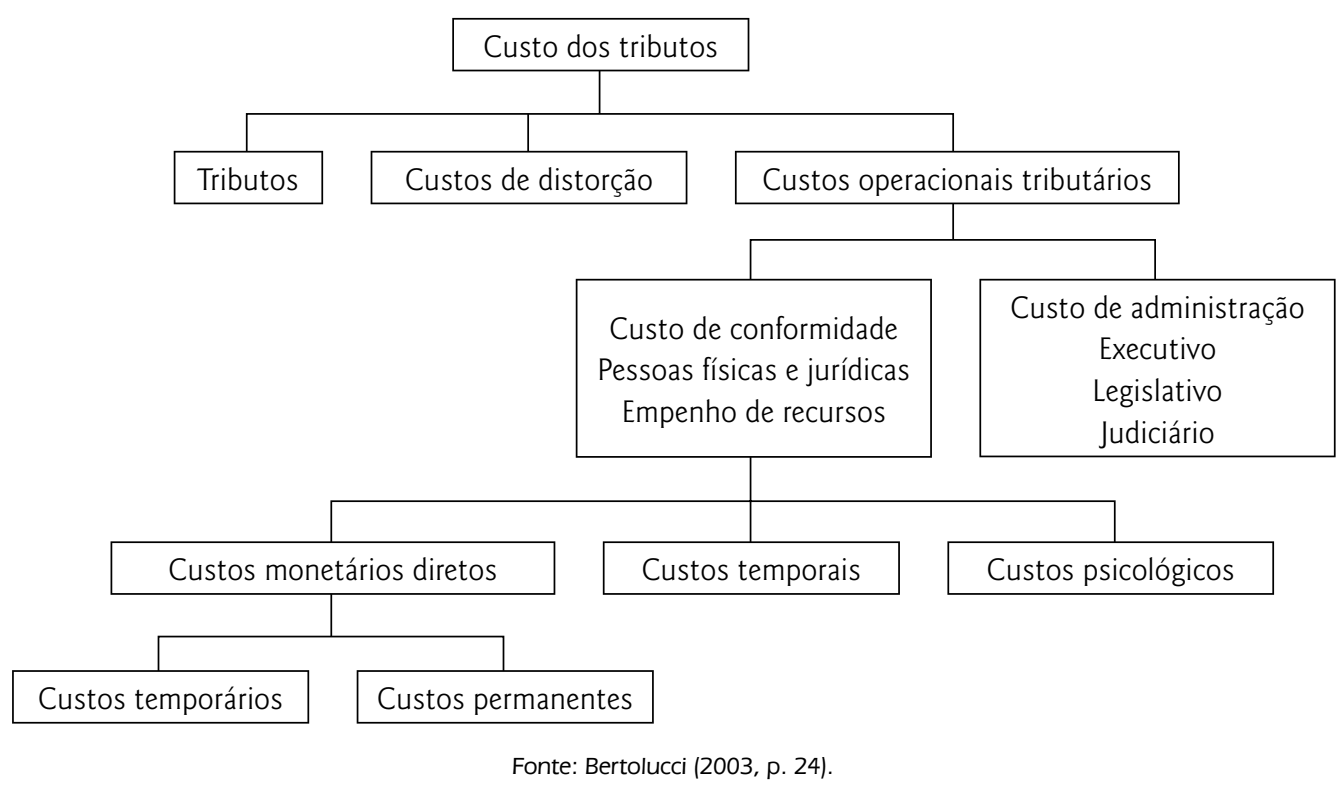

Figura 1

Custos dos Tributos

Companhias Abertas no qual as empresas estão separadas por categorias de receita bruta e cujos Custos de Conformidade, em relação ao seu valor adicionado (que corresponde a seu PIB), se apresentaram conforme a Tabela $I \mathbf{0}$.

O primeiro aspecto que chama a atenção é a regressividade dos Custos de Conformidade: nas empresas menores - que têm receita bruta média de $\mathrm{R} \$ 38$ milhões por ano - o custo de conformidade é 7,7 vezes superior à média de todas as empresas e 24 vezes maior que o custo das maiores empresas. Como são as empresas menores as grandes geradoras de empregos, os Custos de Conformidade desestimulam a criação de empregos, pois oneram desproporcionalmente essas entidades.

O segundo aspecto é o desperdício: utilizando-se a média das empresas - que certamente é conservadora em relação à média nacional, pois as companhias abertas são muito maiores que a média das empresas brasileiras - e aplicando-se a incidência de 0,75\% ao PIB de 2003 infor- mado pelo IBGE (2004), no valor de R \$ 1.5 I 4.924 milhões, chega-se ao custo total de $R \$ 1$ I,4 bilhões desperdiçados pelo País, só naquele ano. Classifica-se como desperdício todo o custo de conformidade, pois não é alocado à atividade produtiva, destinando-se exclusivamente a cumprir determinações legais sem contrapartida em benefícios econômicos.

Por sua vez, os custos do Poder Público com a administração tributária têm sido estudados e divulgados sem que uma metodologia uniforme os torne comparáveis ou, nos Países Federativos como os Estados Unidos da América, sem informações que permitam entender o custo global dessa atividade. Nos Congressos de Rio de Janeiro, Oxford e Sydney, não houve menção por parte dos representantes daquele país a respeito dos custos de Estados - relativos aos impostos sobre o consumo e sobre a renda - e aos Municípios - relativos aos impostos sobre a propriedade.

Tabela 1 Custos de Conformidade no Brasil

\begin{tabular}{l|c} 
CATEGORIA DE RECEITA BRUTA & INCIDÊNCIA SOBRE O PIB \\
\hline ATÉ R\$ 100 MILHÕES & $5,82 \%$ \\
\hline DE R\$ 100 A 1.000 MILHÕES & $1,88 \%$ \\
\hline DE R\$ 1.000 A 5.000 MILHÕES & $1,25 \%$ \\
\hline ACIMA DE R\$ 5.000 MILHÕES & $0,24 \%$ \\
\hline TODAS AS EMPRESAS & $0,75 \%$
\end{tabular}

Fonte: Bertolucci (2003, p. 139). 


\section{PANORAMA MUNDIAL DOS CUSTOS DE ARRECADAC̣ÃO}

\subsection{A Administração Tributária no Reino Unido}

No Reino Unido, há duas entidades que fazem a administração tributária e que são a Inland Revenue e a Customs and Excise.

A Inland Revenue, em seu relatório anual para 2001/02, informa que o custo total de arrecadação de impostos, contribuições à previdência social e de administração dos créditos tributários para o período 2001/02 foi de 1,16\% da arrecadação. Nesse período, o custo total desse departamento foi de $\$ 2,5$ bilhão para uma arrecadação de 2 I 4,0 bilhões de libras esterlinas (2004, p. 102).

A Customs and Excise tem relatório mais recente, relativo a 2003, no qual analisa seu desempenho. Nesse período, o custo total do departamento foi de \$ I, I bilhão para uma arrecadação de \$108,7 bilhões de libras esterlinas, com custo de I,01\% da arrecadação (2004, p. 55).

Embora os valores pertençam a períodos diferentes, apenas a título ilustrativo, calculou-se o custo total da Administração Tributária no Reino Unido que alcançou \$ 3,6 bilhões, para uma arrecadação de \$322,7 bilhões de libras esterlinas, incidindo em I, I 1\% da arrecadação. As variações de custos e de arrecadação têm sido pequenas de ano para ano, permitindo que se faça essa estimativa.

O Banco Mundial (2005) informa a receita tributária do governo central, em 2003, de 36,0\% do PIB.

\subsection{A Administração Tributária no Canadá}

Vaillancourt e Reid (I 989, p. 27 I - 272), em Congresso da International Fiscal Association realizado no Rio em 1988, falaram da estrutura tributária do Canadá que está dividida, na Administração Tributária, em dois níveis: o federal e o local.

O fisco federal arrecada impostos diretos e indiretos enquanto o local arrecada só impostos diretos. Impostos de importação são cobrados pelo fisco federal, impostos sobre a propriedade são cobrados pelo fisco local, enquanto o imposto de renda das pessoas físicas e jurídicas e os impostos sobre vendas são arrecadados por ambos.

Os autores informam que a arrecadação total do ano de I 986 foi de \$20 I bilhões de dólares canadenses (I 989, p. 268) para $\$ 1,3$ bilhão de custos de Administração Tributária federal e \$ 405 milhões das Administrações locais, no total de $\$ 1,7$ bilhões, equivalentes a 0,8\% da arrecadação (I 989, p. 272).

O Banco Mundial (2005) informa a receita tributária do governo central, em 1995 e em 2003, de 20,6\% e 20,0\% do PIB.

\subsection{A Administração Tributária nos Estados Unidos}

O Internal Revenue Service (IRS) (2003, p. I6), a Administração Tributária Federal dos Estados Unidos, publica um relatório sobre suas atividades, no qual trata de problema relativo ao seu sistema de informação, esclarecendo que não permite produzir informação confiável necessária para preparar demonstrações financeiras de acordo com os princípios contábeis federais. Além disso, esse sistema não produz informação confiável para a contabilidade de custos. Conclui que, sem informação confiável, não é possível mensurar a efetividade das atividades de arrecadação e controle de tributos e julgar se os recursos estão alocados apropriadamente entre prioridades que competem entre si. Finalmente, enfatiza que informação confiável sobre a relação custo-benefício é necessária para assessorar o Congresso e para ajudá-lo a tomar decisões bem fundamentadas relativamente a níveis e usos de recursos.

A arrecadação de tributos federais do ano de 200 I foi de US\$2. 124 bilhões (2003, p. 66) e a incidência do custo de arrecadação da ordem de 0,44\%.

O Banco Mundial (2005) informa a receita tributária do governo central, em 2003, de 17,4\% do PIB.

\subsection{A Administração Tributária na Austrália}

O Australian Taxation Office (ATO), a administração tributária da Austrália, divulgou, em seu Annual Report 2002-2003, os dados de arrecadação em custos da administração tributária (2004):

a) Arrecadação: \$ 185.044 milhões

b) Custos de administração: 2.215 milhões

Logo, a incidência dos custos de administração foi de 1,20\% sobre a arrecadação. O ATO informa ter empregado 19.473 funcionários no período, contra uma previsão de 20.500 que havia sido orçada.

Um aspecto que se percebe na Administração Tributária de alguns países, principalmente os de origem anglo-saxônica, é o interesse pela qualidade dos serviços e pelo atendimento dos contribuintes, que são tratados como clientes. Prova disso é o Annual Report editado pelo Australian Taxation Office. Apresenta tópico relativo à performance conseguida em relação a padrões de qualidade almejada, com itens como os indicados, na tabela $2 \boldsymbol{\theta}$, a título de exemplo (2004, p.49).

Percebe-se uma atitude voltada ao aperfeiçoamento das rotinas tributárias e a transparência, tanto de eventos bem sucedidos - como o processamento de declarações eletrônicas que atingiu 96,5\% da meta - quanto de deficiências, tais como os recursos de autuações, com apenas $77,4 \%$ de atingimento.

Outra demonstração do interesse da Administração Tributária da Austrália pelo aperfeiçoamento do sistema tributário como um todo corresponde ao capítulo do $A n$ nual Report dedicado aos compliance costs of taxation, que são os custos de conformidade dos contribuintes.

O Banco Mundial (2005) informa a receita tributária do governo central do país, em 2003, de 26,5\% do PIB. 
Tabela 2 Australian Taxation Office

Performance sobre padrões de serviço 2000 - 2003

\begin{tabular}{l|c|c|c|c|c}
\multicolumn{1}{c|}{ TIPO DE SERVIÇO } & PADRÃO & \multicolumn{2}{c|}{ \% DE ATINGIMENTO } & \% META \\
\hline & & $\mathbf{2 0 0 0 - 0 1}$ & $\mathbf{2 0 0 1 - 0 2}$ & $\mathbf{2 0 0 2 - 0 3}$ & $\mathbf{2 0 0 2 - 0 3}$ \\
\hline Processar declarações eletrônicas & 14 dias & 91,0 & 95,1 & 96,5 & 95,0 \\
\hline Processar declarações manuais & 42 dias & 94,3 & 90,2 & 96,1 & 90,0 \\
\hline Devolução de tributos pagos a maior & 28 dias & 90,4 & 96,6 & 97,0 & 90,0 \\
\hline Recursos de autuações & 56 dias & 69,2 & 52,9 & 77,4 & 65,0 \\
\hline Correspondência geral & 28 dias & 77,9 & 80,7 & 87,7 & 84,0 \\
\hline Serviço de consultas telefônicas & 2 a 5 minutos & 86,8 & 69,4 & 89,1 & 80,0 \\
\hline Erros administrativos & 14 dias & 57,7 & 64,1 & 83,6 & 65,0
\end{tabular}

Fonte: Australian Taxation Office (2004, p. 49).

\subsection{A Administração Tributária na França}

Feydeau e Kulbokas (1989, p. 36 I - 381) apresentam o sistema tributário francês e informam que a incidência dos tributos sobre o PIB é de 45,3\%, um dos mais altos do mundo e que estão, assim, distribuídos:

$\begin{array}{lr}\text { Impostos do Estado } & 18,0 \% \\ \text { Taxas parafiscais } & 2,0 \% \\ \text { Impostos locais } & 5,5 \% \\ \text { Seguridade Social } & 19,8 \% \\ \text { Total } & 45,3 \%\end{array}$

Os autores não têm informações precisas a respeito dos custos da Administração Tributária, informando que, em 1986, havia 83.794 agentes com um orçamento de 9,8 bilhões de francos franceses e que o orçamento do Estado para 1998 era de \$ I.I 79 bilhões (1989, p. 362 - 364). Sendo as estimativas corretas, o custo de administração incidiria em $0,83 \%$ sobre o orçamento.

O Banco Mundial (2005) informa a receita tributária do governo central do país, em 1995 e em 2003, de 44,0\% e $43,9 \%$ do PIB.

\subsection{A Administração Tributária em Israel}

Freidkes e Gavish (1989, p. 403 - 418) informam que a Administração Tributária de Israel é dividida em dois setores:

a) Departamento de Imposto de Renda e de Imposto sobre a Propriedade e

b) Alfândega e Imposto sobre o Valor Adicionado.

Informam que, em 1987, havia 7.060 funcionários e que o custo total da Administração Tributária foi de NIS 258 milhões. Assim, o custo percentual em relação à receita é de 0,163\% e a receita estimada em \$158, 3 bilhões.

Os autores fazem uma afirmação não mencionada nos estudos dos outros paises, ou seja, de que os custos dos tribunais não puderam ser identificados para integrar o custo de arrecadação, mas afirmam que é um custo baixo em relação ao custo total do Judiciário.

O Banco Mundial (2005) informa a receita tributária do governo central, em 2003, 44,4\% do PIB.

\subsection{A Administração Tributária no Japão}

Aoki (1 989, p. 437 - 455) informa que, em 1986, os custos da Administração Tributária foram de 434 bilhões de ienes e a arrecadação de 397.962 bilhões de ienes, correspondendo a 0,109\% de incidência. Esses foram os custos da National Tax Administration e abrangem somente os tributos arrecadados por essa entidade, que contava com 52.916 funcionários naquele ano.

Com relação aos tributos locais, a informação é de que os custos foram de 652 bilhões de ienes para uma arrecadação de 24.628 bilhões de ienes, incidindo em 2,64\% sobre a arrecadação. $O$ autor explica que os custos de arrecadação dos tributos locais são elevados porque esses tributos apresentam maior dificuldade de arrecadação.

Somando os custos e arrecadação dessas duas entidades, obtêm-se os seguintes montantes:

a) Custos: 1.086 bilhões de ienes e

b) Arrecadação: 422.590 bilhões de ienes.

Dessa forma, chega-se a uma incidência de 0,26\% de custos administrativos em relação à arrecadação.

\subsection{A Administração Tributária na Noruega}

Nicolaissen (1989, p. 46 I - 478) informa que o nível de tributação em relação ao PIB, em 1987, foi de 47,9\% e sua distribuição como apresentada na tabela $3 \bullet$. O autor afirma que "é impossível calcular com exatidão os custos do Poder Público relacionados a todos os aspectos de administrar o sistema tributário", pois há comprometimento de vários setores governamentais, como o Executivo e o Legislativo, envolvidos com a preparação da legislação tributária; a polícia e a promotoria pública, envolvidas nos processos das violações das leis tributárias etc. Como estimativa disponível, apresenta, para 1987, um total de 10.799 funcionários com um total de custos de $\$ 2.803$ milhões de coroas dinamarquesas, e uma incidência de 1,05\% sobre a arrecadação.

O Banco Mundial (2005) informa a receita tributária do governo central, em 2003, de 47,6\% do PIB. 
Tabela 3 Noruega: Incidência de impostos em relação à tributação

\begin{tabular}{l|c}
\multicolumn{1}{c|}{ TIPO DE TRIBUTO } & PORCENTAGEM \\
\hline Imposto de renda pessoa física & $36,8 \%$ \\
\hline Imposto de renda pessoa jurídica & $3,4 \%$ \\
\hline Imposto sobre o valor adicionado & $21,8 \%$ \\
\hline Outros impostos & $38,0 \%$ \\
\hline Total da tributação & $100,0 \%$
\end{tabular}

Fonte: Nicolaissen (1989, p 461-478).

\subsection{A Administração Tributária em Portugal}

Carvalho (1989, p. 518 - 519) afirma ser impossível conhecer o custo da Administração Tributária, pois há vários setores do governo envolvidos, entre os quais, a $\mathrm{DGCl}$ - Direção Geral de Contribuições e Impostos, a Direção Geral de Aduanas, a Direção Geral do Tesouro, a Inspeção Geral de Finanças e o Instituto da Informática que, porém, não se dedicam somente aos aspectos tributários. $\mathrm{O}$ autor estima que, aproximadamente, 15.000 pessoas estejam envolvidas. Por ser o departamento mais importante, cita os números da $\mathrm{DGCl}$ e a arrecadação direta desse departamento, que foram em 1987:

$\begin{array}{ll}\text { Receita tributária: } & 705.063 \text { mil escudos } \\ \text { Despesa: } & 18.143 \text { mil escudos } \\ \text { Incidência percentual: } & 2,6 \%\end{array}$

Dada a incidência muito elevada, comparativamente aos estudos dos outros países, é possível que haja algum problema no método de cálculo apresentado pelo autor.

O Banco Mundial (2005) informa a receita tributária do governo central, em 2003, de 37,7\% do PIB.

\subsection{A Administração Tributária na Suécia}

Norrman e Malmer (1989, p. 563 - 586) afirmam que se acredita que os custos operacionais tributários, medidos em relação ao $\mathrm{PIB}$, não superem a $1 \%$. Considerando que, em I 987, a tributação incidiu em 54,8\% do PIB, a incidência dos custos operacionais tributários sobre a arrecadação seria de 1,82\%, e a relação dos custos da Administração Tributária sejam a metade dos Custos de Conformidade - como no Reino Unido -, os custos de administração poderiam ser estimados em 0,61\% da arrecadação e 0,33\% do PIB.

Os autores informam que os funcionários pertencentes à administração tributária eram 13.566, no período 1986 87 (I 989, p. 568). Relatam que foi feita, em I 970, a primeira tentativa de mensuração dos custos da Administração Tributária. Os auditores do Parlamento relataram que foi muito difícil levantar os dados, pois a previsão orçamentária e a contabilidade não mostravam a relação entre as várias funções das autoridades e os custos correspondentes. Conseqüentemente, os cálculos tiveram que ser baseados, em grande parte, em estimativas e modelos.
Somente em 1983 foi editado o ESO Report, relativo ao período orçamentário 1981-82, trazendo os custos do sistema de Administração Tributária e também os relativos a outras autoridades envolvidas com aspectos tributários, tais como os tribunais e outras áreas do Judiciário. Os autores esclarecem que, apesar da evolução da contabilidade, vários cálculos foram feitos com métodos estatísticos ou por estimativa. Em alguns casos, a autoridade envolvida participou da estimativa, quando só parte da atividade era ligada à tributação (1989, p. 576). Os valores apresentados por esse relatório são, para o ano de 1981-82, em miIhões de coroas suecas:
Arrecadação:
283.467
Custos da administração tributária:
2.878
Porcentagem:
$1 \%$

Pela estimativa inicial dos autores, percebe-se que a reforma tributária realizada na Suécia na década de 80 conseguiu reduzir em $40 \%$ os custos, que eram de I $\%$ da arrecadação em 198|-82, para 0,6 I\% em 1987.

O Banco Mundial (2005) informa a receita tributária do governo central, em 2003, de 37,7\% do PIB.

\subsection{A Administração Tributária na Suiça}

Gremaud (1989, p. 595 - 619) afirma que as informações estatísticas relativas ao custo de arrecadar impostos são quase inexistentes naquele país. Para avaliar esse custo, a autora pesquisou a administração federal das contribuições e também os 26 cantões e meio-cantões da Suíça. Não usou um só cantão como padrão por causa das suas diferenças. A autora alerta para se ter prudência na interpretação dos resultados dos cantões pelos seguintes motivos (1 989, p. 606):

a) A estrutura econômica e política de cada cantão varia consideravelmente, assim como variam os tributos existentes, devendo-se considerar cada cantão como um Estado independente, à parte;

b) Os sistemas contábeis são diferentes e alguns cantões não estão em condições de estimar o custo de itens como aluguéis, informática e móveis e utensílios;

c) Somente 18 cantões responderam à pesquisa.

Para 1986, o custo médio dos cantões foi estimado em I,37\% da sua arrecadação. 
Com relação à Administração Federal de Contribuições, a resposta à pesquisa foi considerada bastante precisa pela autora. Seu custo foi de 64,6 milhões de francos suiç̧os para uma arrecadação de 15.777 milhões de francos suíços, correspondendo a 0,4\% de incidência (1 989, p. 608).

O Banco Mundial (2005) informa a receita tributária do governo central, em 1995 e em 2003, de $22,7 \%$ e $18,8 \%$ do PIB.

\subsection{A Administração Tributária na Nova Zelândia}

O New Zealand Inland Revenue Department (IRD) é o órgão de Administração Tributária da Nova Zelândia. Em seu site, não foi possível encontrar informações sobre os custos efetivos da administração tributária e sua incidência sobre a arrecadação, mas há informações de interesse para o desenvolvimento e melhoria dessa atividade (2004). Em relatório relativo a auditorias realizadas, o IRD informa que a receita tributária prevista para 2002-03 foi de \$4I.569 milhões e seu corpo de funcionários era constituído de 4.800 pessoas, das quais $88 \mathrm{I}$ atuando em auditoria, para detectar casos de não conformidade e para impedir esses casos no futuro (2004).

Na parte 1, item 1.17 do relatório sobre auditorias, o IRD declara que:

Restrições de tempo e de recursos também nos impediram de realizar o benchmarking da atividade de auditoria do nosso contribuinte com outras administrações tributárias ao redor do mundo. Apesar disto poderia ter sido um exercício interessante e potencial- mente útil, a complexidade das administrações tributárias e a legislação diferente que operam iriam tornar o benchmarking demorado e dispendioso.'

No item 2.2 do relatório, há uma demonstração da importância dada aos contribuintes pelo IRD em sua declaração sobre seus principais deveres:

a missão de arrecadar ao longo do tempo a maior arrecadação líquida possível nos termos da lei, levando em consideração os recursos disponíveis ao responsável pela arrecadação, a importância de promover a conformidade de todos os contribuintes e os custos de conformidade incorridos pelos contribuintes. (O grifo é nosso) ${ }^{2}$

Ou seja, o tema do custo de conformidade dos contribuintes não só é conhecido como faz parte dos principais deveres da Administração Tributária da Nova Zelândia.

Com relação às auditorias dos contribuintes, o item 4.12 do relatório esclarece que o Taxpayer Audit Selection System (TASS) é processado duas vezes por ano, em dezembro e junho, sobre todos os tipos de declarações, para gerar uma seleção de todos os contribuintes potencialmente candidatos à auditoria. Usando 26 queries, a base de dados do IRD seleciona esses contribuintes. Os arquivos gerados, dessa forma, são analisados pelos auditores com base em uma risk analysis e completam uma avaliação de risco que os apóia na seleção final.

O Banco Mundial (2005) informa a receita tributária do governo central, em 2003, de 36,8\% do PIB.

\section{A PESOUISA DOS CUSTOS DE ADMINISTRAÇÃO TRIBUTÁRIA NO BRASIL}

A primeira questão que se propõe refere-se a quais áreas deveriam ser incluídas nos custos de arrecadação de tributos, como parte dos custos de Administração Tributária. Como se viu, alguns países entendem que esses custos se limitam às Administrações Tributárias propriamente ditas, ou seja, às atividades diretamente ligadas à administração dos tributos. Em outros países, viu-se que englobam, também, os custos dos tribunais administrativos ou judiciais, da polícia etc.

Bertolucci (2005, p 60) entende que, no Brasil, os custos de arrecadação devem incluir todos os recursos destinados a questões tributárias, ou seja, recursos que não seriam necessários se o tributo não existisse. Sob esse enfoque, devem ser incluídos custos das seguintes áreas:

a) No Poder Executivo

- Secretaria da Receita Federal (SRF);

- Procuradoria Geral da Fazenda Nacional (PGFN) pela parte que se dedica à arrecadação de tributos;
- Instituto Nacional do Seguro Social (INSS) pela parte que se dedica à arrecadação de tributos;

b) No Poder Legislativo, pela parte que se dedica à legislação de tributos;

c) No Poder Judiciário, pela parte que se dedica ao julgamento de questões tributárias.

Com relação ao Poder Legislativo, o autor deste trabalho entende que, em situações normais, nas quais não se discutem reformas tributárias, o empenho do Legislativo com a legislação tributária é relativamente modesto. Além disso, a dificuldade para se definir um parâmetro de atribuição dessas despesas à atividade tributária também é um obstáculo para o cálculo desses custos. Conseqüentemente, o autor deste trabalho optou por não incluir esses custos na pesquisa.

No Poder Judiciário, a situação é diferente: a administração pública no Brasil, principalmente antes do advento

\footnotetext{
I Time and resource constraints also prevented us from benchmarking IRD's taxpayer audit activity with other tax jurisdictions around the world. While this would have been an interesting and potentially useful exercise, the complexity tax departments and the different legislation they operate under would have made meaningful benchmarking time-consuming and expensive.

2 The duty to collect over time the highest net revenue that is practicable within the law, having regard to the resources available to the commissioner, the importance of promoting compliance by all taxpayers, and the compliance costs incurred by the taxpayers.
} 
da Lei Complementar $n^{\circ}$. 101 de 4 de maio de 2000, conhecida como Lei de Responsabilidade Fiscal (2000), não tinha compromisso com o equilíbrio fiscal e resolvia seus problemas de caixa com aumentos de tributos, muitas vezes de forma ilegal, provocando reações em cadeia por parte dos contribuintes que recorriam aos tribunais para defender seus direitos. Não é só nos temas tributários que o Poder Público é parte nos processos judiciais: também em outros temas, é o principal causador da grande quantidade de processos em andamento nos tribunais e, conseqüentemente, contribui para a morosidade do Judiciário. Dessa forma, é necessário incluir parcela dos custos do Poder Judiciário nos custos de arrecadação de tributos.

A pesquisa dos custos da Administração Tributária da União, no Brasil, apresenta um panorama totalmente diferente das autoridades tributárias dos países desenvolvidos. Nesses países, os sites das Administrações Tributárias apresentam relatórios anuais com os balanços patrimoniais, custos de operação, relatórios de auditoria, definição de políticas de atendimento ao contribuinte, departamentos responsáveis pelo acompanhamento dos custos de conformidade com o objetivo de reduzi-los, e programas de longo prazo das atividades e investimentos.

No Brasil, o autor deste trabalho teve experiência inversa: a pesquisa teve início em setembro de 2002 e os contatos com os vários representantes do Poder Público se repetiram até junho de 2005. Com raras exceções, a informação desejada não estava disponível. Em uma ocasião, a informação existia, mas havia ordens superiores para não disponibilizála, mesmo para uma pesquisa científica. A Secretaria do Tesouro Nacional apoiou a pesquisa e, mesmo reconhecendo dificuldades no levantamento das informações, prestou-se a entregá-las ao autor deste trabalho. Pelas informações fornecidas, o orçamento público não permite que se controlem os dispêndios efetivos dos vários entes da União, pois não há a identificação desses entes por centros de custo, os custos de pessoal são concentrados no Ministério, sem aberturas que permitam sua atribuição de forma analítica. Em várias ocasiões, o autor deste trabalho recebeu relatórios do SIAF, o Sistema Orçamentário da União, que resultaram incompreensíveis, parciais e inúteis para a pesquisa. Informação sobre o mesmo aspecto, provenientes de duas fontes diversas, resultaram diferentes.

Relatórios anuais editados pela Procuradoria Geral da Fazenda Nacional - PGFN trazem informações diferentes para os mesmos fatos, ou seja, o que se informou no ano de 2002 é modificado no relatório de 2003. O relatório de 2002, à página 58, informa que as despesas da PGFN, em 2002, foram de $\mathrm{R} \$ 62.419 .886,81$. No relatório de 2003, à página 54 , consta que as despesas da PGFN, em 2002, foram de $R \$ 34.640 .288,00$.

Nos Tribunais Federais, houve de tudo: desde solicitação de que o autor escrevesse para o Presidente do Tribunal Federal da $4^{a}$ Região, sem jamais ter recebido resposta, como muita disposição de fornecer informações, mas reconhecendo que não havia padronização nas estatísticas das várias regiões. No período da pesquisa de campo do autor, os responsáveis pelas estatísticas das várias regiões fizeram uma reunião para estudar a padronização dessas informações. Porém, pela informação recebida, os Tribunais Superiores - Superior Tribunal de Justiça (STJ) e Supremo Tribunal Federal (STF) - não iam participar desse encontro. A falta de padronização e a inexistência de controles adequados para as várias naturezas de processos fazem pensar que não há interesse em compreender o que vem ocorrendo no Judiciário ao longo dos anos.

A Secretaria do Tesouro Nacional, um dos órgãos mais cooperadores com a pesquisa deste autor, demonstrou sua impossibilidade de controlar as despesas efetivas dos entes envolvidos na Administração Tributária, pois chegou a informar que os custos anuais de pessoal da Secretaria da Receita Federal corresponderiam a R\$ 16.865.630,68. No entanto, informação extra-oficial da Secretaria da Receita Federal relatava que estavam lotados cerca de 14.500 agentes fiscais e mais 3.000 funcionários do SERPRO - Serviço de Processamento de Dados da União, além de 3.000 funcionários burocráticos. Evidentemente, não era possível que 20.500 funcionários de alto nível provocassem uma despesa de pessoal tão baixa, correspondendo a uma remuneração média anual de $R \$ 822,71$. Foi necessário que o autor levantasse uma estatística do CIAT - Centro Interamericano de Administrações Tributárias relativa ao ano de 1999 - com custos de pessoal de R\$1,2 bilhões - para poder estimar a despesa atual da Secretaria da Receita Federal.

Outro aspecto que demonstra a atitude não transparente da Secretaria da Receita Federal é o próprio site que, na década de 90, apresentou vários estudos da sua estrutura organizacional, mas publicou muito pouco nos últimos anos.

Um fato auspicioso é que o BNDES - Banco Nacional de Desenvolvimento Econômico e Social criou um Programa de Modernização da Administração Tributária e Gestão dos Setores Sociais Básicos - PMAT (2005) com o objetivo de financiar os Municípios a se organizarem em suas Administrações Tributárias modernizando-as e fazendo com que obtenham mais recursos, estáveis e não inflacionários.

Afonso et al. (1 998, p. 24) tratam desse tema apresentando os vários aspectos desse programa e relacionando alguns Municípios que já o implantaram, com um aumento sensível de suas arrecadações. Alguns exemplos são:
Recife
Petrolina
Cuiabá
$+51,4 \%$
Fortaleza
$+100,0 \%$
$+96,6 \%$
$+45,0 \%$
Rio de Janeiro
$+24,8 \%$

Informações mais analíticas relativas aos vários entes federais apresentados em resumo, a seguir, podem ser obtidas em Bertolucci (2005).

\subsection{A Secretaria da Receita Federal}

Apesar da insistência do autor deste trabalho em obter informações pormenorizadas a respeito dos custos da Secretaria da Receita Federal (SRF), não houve interesse por parte desse ente em dar essa abertura para a pesquisa. Finalmente, em meados de 2005, a SRF forneceu seu custo 
total do exercício de 2004 informando que não tinha esse dado para o ano de 2003. O custo total informado foi de $\mathrm{R} \$ 2.878 .961 .059,13$ para uma arrecadação de tributos federais de $R \$ 322,5$ bilhões, correspondendo a 0,89\% da arrecadação. Essa informação será utilizada neste trabalho, em substituição a valor eventualmente estimado, em virtude da falta de elementos para se realizar esse cálculo.

\subsection{Procuradoria Geral da Fazenda Nacional (PGFN)}

$A$ atividade da PGFN não se limita à tributação, sendo necessário excluir parcela de recursos que não estão sendo alocados nessa atividade. Em contatos informais, o autor foi informado de que a atividade não tributária é relativamente pequena e que poderia ser estimada em, no máximo, $10 \%$ do total, com $90 \%$ relativa a tributos. Não foi possível obter a confirmação formal dessa estimativa que, no entanto, será adotada por este trabalho, na ausência de informações mais precisas.

$\mathrm{O}$ autor deste trabalho prefere adotar os valores informados pela STN e que são apresentados na tabela $4 \boldsymbol{O}$, em milhões de reais, em virtude de inconsistências nas informações da PGFN.

\subsection{Instituto Nacional do Seguro Social (INSS)}

Os custos de arrecadação de tributos pelo INSS em 2003, são os apresentados na tabela $5 \mathbf{0}$.

\subsection{O Poder Judiciário}

A Secretaria do Tesouro Nacional (STN) apresentou um quadro das despesas do Poder Judiciário, no qual estão separadas suas principais divisões:
a) O Supremo Tribunal Federal (STF);
b) O Superior Tribunal de Justiça (STJ);
c) A Justiça Federal de $1^{\circ}$ Grau;
d) Os Tribunais Federais das várias Regiões;
e) A Justiça Militar;
f) A Justiça Eleitoral;
g) A Justiça do Trabalho;
h) A Justiça do Distrito Federal.

Dessas divisões, somente os itens "a", "b" "c" e "d", tratam de temas tributários. Além disso, nos Tribunais Federais das várias Regiões, há muitas dotações a universidades e fundações que foram excluídas dos valores levados em consideração. Da mesma forma, foram excluídos os valores destinados ao Banco Central, Fundo de Previdência, Instituto Nacional de Colonização e Reforma Agrária (INCRA), Departamento Nacional de Obras Contra as Secas (DNOCS) e IBGE, entre outros.

Dessa forma, os montantes levados em consideração para o Poder Judiciário, para o exercício de 2003, em miIhões de reais, são os apresentados na Tabela 60.

$O$ autor deste trabalho realizou pesquisa de campo contatando os serviços de estatística dos vários tribunais com o objetivo de conseguir parâmetros para a atribuição dos custos tributários. Verificou-se que não há padronização nas informações estatísticas tratadas pelas várias Regiões e que se está iniciando, para 2005, um projeto de padronização.

Chama a atenção o envolvimento do Poder Público com processos em andamento nos tribunais federais. Bertolucci (2005, p. 86) apresenta estatística do Tribunal da $3^{\text {a }}$. Região, com mais de $90 \%$ dos processos em andamento envolvendo a União que é a grande responsável pela morosidade dos tribunais. A Tabela $7 \bullet$ mostra esse aspecto.

Tabela 4 Procuradoria Geral da Fazenda Nacional Despesas Efetivas no Exercício de 2003 (em milhões de reais)

\begin{tabular}{l|c} 
GRUPO DE DESPESA & VALOR \\
Pessoal e encargos sociais & 19 \\
\hline Outras despesas correntes & 179 \\
\hline Investimentos & 3 \\
\hline TOTAL & 201
\end{tabular}

Fonte: STN.

Tabela 5 Custos de Arrecadação do INSS em 2003 (em milhões de reais)

\begin{tabular}{l|c} 
TIPO DE CUSTO & VALORES \\
\hline Custo do pessoal de fiscalização e arrecadação & 623,6 \\
\hline Custos diretos da atividade & 179,1 \\
\hline Custos gerais atribuídos & 220,8 \\
\hline TOTAL & $1.023,5$
\end{tabular}

Fonte: Ministério da Previdência. 
Tabela 6 || Despesas do Poder Judiciário - Exercício 2003

(milhões de reais)

\begin{tabular}{|c|c|c|c|c|c|}
\hline ORGÃO & PESSOAL & DESPESAS & INVESTIMENTOS & INVERSÕES & TOTAL \\
\hline Supremo Tribunal Federal & 139 & 54 & 6 & 0 & 199 \\
\hline Superior Tribunal de Justiça & 332 & 64 & 8 & 0 & 404 \\
\hline Justiça Federal de Primeiro Grau & 1.576 & 318 & 77 & 2 & 1.973 \\
\hline Tribunal 1 a Região & 226 & 134 & 12 & 7 & 379 \\
\hline Tribunal 2 a Região & 165 & 59 & 2 & 5 & 231 \\
\hline Tribunal $3{ }^{a}$ Região & 192 & 149 & 3 & 58 & 402 \\
\hline Tribunal $4{ }^{\text {a }}$ Região & 194 & 490 & 2 & 11 & 697 \\
\hline Tribunal 5 a Região & 146 & 24 & 1 & 1 & 172 \\
\hline TOTAL & 2.970 & 1.292 & 111 & 84 & 4.457 \\
\hline
\end{tabular}

Fonte: STN.

Tabela 7 - Tribunal Regional Federal - 3a Região

Processos julgados no período 1989 - 2003

\begin{tabular}{l|c|c}
\multicolumn{1}{c|}{ MATÉRIA } & TOTAL NO PERÍODO & PORCENTAGEM \\
\hline Previdenciária & 540.571 & $59,0 \%$ \\
\hline Tributária & 309.520 & $33,8 \%$ \\
\hline Criminal & 16.048 & $1,8 \%$ \\
\hline Outras & 49.831 & $5,4 \%$ \\
\hline TOTAL & 915.970 & $100,0 \%$
\end{tabular}

Fonte: Bertolucci (2005, p. 86).

Com base nas estatísticas apuradas por Bertolucci (2005, p. $8 \mathrm{I}-9 \mathrm{I}$ ), os processos tributários do primeiro grau, a ponderação de $43,55 \%$ será utilizada para atribuir os custos do primeiro grau. Chama a atenção, porém, a diferença sensível na incidência da Primeira e Terceira Regiões, com mais de $50 \%$ de processos de natureza tributária, comparativamente com as outras Regiões, com incidência média próxima dos $30 \%$. Com relação ao segundo grau, a ponderação disponível é a da Terceira Região: $25,35 \%$. O STJ e STF ficam com as incidências informadas pelos órgãos de estatística daqueles tribunais, ou seja, 16,3\% e 16,4\% respectivamente.

\subsection{Resumo dos Custos verificados ou estimados}

O resumo dos custos verificados ou estimados pode ser visto na tabela 8 . Nela, chama a atenção a alta incidência do Judiciário Federal que dedica $30,97 \%$ de seus recursos para os processos de natureza tributária.

\subsection{Comparação com outros Países}

A tabela 90 , mostra a incidência dos custos de administração dos vários países, em relação à arrecadação tributária.

Como se viu nos custos da administração tributária no Brasil, se fossem excluídos os custos do Poder Judiciário porque tivessem sido reduzidos a níveis insignificantes, a incidência de custos sobre a arrecadação ficaria reduzida a $0,9 \%$, em linha com outros países mais evoluídos como Suécia, Canadá ou França e inferior ao Reino Unido. Verdade seja dita, os custos daqueles países são globais enquanto, no Brasil, não se incluíram os custos dos Estados e Municípios. Note-se que, nos Estados Unidos, a incidência dos custos da administração tributária federal sobre a arrecadação é de 0,44\%, menos da metade do custo no Brasil.

\section{CUSTOS DE ADMINISTRACÃO TRIBUTÁRIA FEDERAL: CONSIDERAÇÕES GERAIS E CONCLUSÕES}

O primeiro aspecto que se observa é o fato de que nem os pesquisadores, nem os administradores tributários têm uma forma de medição padronizada dos custos de administração. Quando se verifica que os custos de conformi- dade dos contribuintes têm métodos consistentes de avaliação, como os mostrados nas conferências do Congresso de Sydney (200I), é estranho constatar que exatamente onde há mais recursos disponíveis - nas Administrações 
Tabela 8 - Resumo das incidências de custos das Administrações Tributárias (valores em milhões de reais)

\begin{tabular}{|c|c|c|c|}
\hline ENTIDADE & CUSTO ANUAL & ATRIBUIÇÃO & CUSTO ATRIBUÍDO \\
\hline 1) Secretaria da Receita Federal & 2.879 & $100,00 \%$ & 2.879 \\
\hline 2) Procuradoria da Fazenda Nacional & 201 & $90,00 \%$ & 181 \\
\hline 3) Instituto Nacional do Seguro Social & 7.503 & $13,64 \%$ & 1.024 \\
\hline Sub-total Poder Executivo & 10.583 & & 4.083 \\
\hline Incidência sobre arrecadação federal & & & $1,01 \%$ \\
\hline \multicolumn{4}{|l|}{ 4) Poder Judiciário } \\
\hline \multicolumn{4}{|l|}{ a) Tribunais de primeira instância } \\
\hline Primeira Região & 379 & $51,65 \%$ & 196 \\
\hline Segunda Região & 231 & $31,72 \%$ & 73 \\
\hline Terceira Região & 402 & $58,66 \%$ & 236 \\
\hline Quarta Região & 697 & $33,01 \%$ & 230 \\
\hline Quinta Região & 172 & $27,30 \%$ & 47 \\
\hline Total primeira instância & 1.881 & & 782 \\
\hline b) Tribunais de segunda instância & 1.973 & $25,35 \%$ & 500 \\
\hline c) Superior Tribunal de Justiça & 404 & $16,30 \%$ & 66 \\
\hline d) Supremo Tribunal Federal & 199 & $16,40 \%$ & 33 \\
\hline Sub-total Poder Judiciário & 4.457 & $30,97 \%$ & 1.381 \\
\hline Incidência sobre arrecadação federal & & & $0,34 \%$ \\
\hline TOTAL & 15.040 & & 5.464 \\
\hline \multicolumn{4}{|l|}{ Arrecadação tributária federal (2003) } \\
\hline Secretaria da Receita Federal & & & 322.555 \\
\hline Instituto Nacional do Seguro Social & & & 80.730 \\
\hline Total & & & 403.285 \\
\hline Incidência sobre arrecadação federal & & & $1,35 \%$ \\
\hline PIB em 2003 & & & 1.514 .924 \\
\hline Incidência sobre o PIB & & & $0,36 \%$ \\
\hline
\end{tabular}

Tabela 9 - Custos de Administração Tributária e incidência sobre a Arrecadação (Valores em bilhões)

\begin{tabular}{|c|c|c|c|}
\hline PAís & ARRECADAÇÃO & DESPESAS DE ADMINISTRAÇÃO & INCIDÊNCIA PERCENTUAL \\
\hline a) Inland Revenue (em 2001) & 214,0 & 2,5 & $1,17 \%$ \\
\hline b) Customs and Excise (em 2002) & 108,7 & 1,1 & $1,01 \%$ \\
\hline Total & 322,7 & 3,6 & $1,12 \%$ \\
\hline Canadá & 201,0 & 1,7 & $0,85 \%$ \\
\hline Estados Unidos ( Em 2001) & $2.124,0$ & 9,3 & $0,44 \%$ \\
\hline Austrália & 185,0 & 2,2 & $1,20 \%$ \\
\hline França & $1.179,0$ & 9,8 & $0,83 \%$ \\
\hline Israel & 158,3 & 0,3 & $0,16 \%$ \\
\hline Japão & $422.590,0$ & $1.086,0$ & $0,26 \%$ \\
\hline Noruega & $2.669,5$ & 2,8 & $0,10 \%$ \\
\hline Portugal & 705,1 & 18,1 & $2,57 \%$ \\
\hline Suécia & 283,5 & 2,9 & $1,02 \%$ \\
\hline
\end{tabular}


(continuação)

\begin{tabular}{l|c|c|c}
\multicolumn{1}{c|}{ PAÍ́ } & ARRECADAÇÃO & DESPESAS DE ADMINISTRAÇÃO & INCIDÊNCIA PERCENTUAL \\
Suiça & & & $1,37 \%$ \\
\hline Custo dos cantões & & & $\mathbf{0 , 4 0 \%}$ \\
\hline Administração Central & & $\mathbf{5 , 5}$ & $\mathbf{1 , 3 5 \%}$
\end{tabular}

Tributárias do mundo inteiro - não se definiu uma forma padronizada de mensurar esses custos.

Com raras exceções, nenhum país inclui nos custos de administração outros custos além dos custos diretos da Administração Tributária, ou seja, do Fisco. Em alguns países, verifica-se que não há uma só Administração Tributária, mas pode haver duas, como no Reino Unido, ou muitas, como nos Estados Unidos que têm estrutura federativa como a do Brasil. Parece haver alguns sinais de que a atuação independente de entes diferentes para a administração de tributos poderia não ser a mais conveniente.

Essa questão se volta para a Administração Tributária no Brasil e leva à pergunta sobre se a atual estrutura do Poder Executivo não poderia ser racionalizada fundindo-se não somente a Secretaria da Receita Federal com a atividade de arrecadação do INSS em um único ente, mas também a Procuradoria Geral da Fazenda Nacional. É possível que a padronização de procedimentos e de sistemas informativos, com bases de dados comuns possa levar a um aperfeiçoamento da atividade com aumento de eficácia. Por iniciativa do Poder Executivo, já se iniciou esse processo de racionalização com a fusão da Secretaria da Receita Federal com o INSS, realizada recentemente.

Outro aspecto a destacar é a abordagem que as várias administrações tributárias dão à transparência de suas atividades. Em alguns casos, como no Reino Unido, Estados Unidos ou Austrália, os relatórios anuais têm mais de 100 páginas nas quais são descritas minuciosamente suas atividades e são medidos os seus desempenhos. São apresentados balanços patrimoniais auditados, medidas de desempenho em relação a metas, atividades voltadas para a redução dos custos de conformidade dos contribuintes, e outras informações destinadas a todos os interessados. No Brasil, parece não haver essa política: o site da Secretaria da Receita Federal mostra estudos desatualizados, de 1997 e 1998, e poucos posteriores a 2000. O INSS apresentava, em junho de 2004, em seu site, a arrecadação de 2002 e não fornecia dados de 2003, já encerrado há 6 meses. A PGFN publica relatórios oficiais anuais nos quais suas despesas para o ano de 2002 são alteradas em 2003 sem nota explicativa. Os problemas de controle orçamentário já mencionados aumentam as dúvidas quanto à qualidade das informações.

Outro aspecto que deve ser comentado são os valores que aparecem nesta pesquisa. Com relação aos custos no Brasil, têm-se:

a) Os depoimentos pessoais recebidos na Secretaria do Tesouro Nacional, que é a Controladoria Geral da União, foram significativos: a cada ano que passa, são feitos progressos na contabilidade da União e no seu controle orçamentário. Porém, há, ainda, uma grande dificuldade de se obterem as informações necessárias e há pouca segurança que essas informações sejam corretas. Essa insegurança transparece, também, nos dados apresentados pela Secretaria da Receita Federal ao Comitê Internacional de Administrações Tributárias (CIAT) onde chega a afirmar que não tem controle sobre as informações dos recursos do Tesouro e "dispomos apenas de estimativas" [ca. 2000].

b) Com relação aos custos dos entes no Brasil, o que mais atrai a atenção é o empenho do Poder Judiciário com questões que envolvem o Poder Público: verifica-se que cerca de $90 \%$ dos casos têm como parte o Poder Público, já excluídos os processos criminais nos quais é parte obrigatória por dever constitucional. Atrai a atenção - mesmo sem ter relação com a tributação - o aumento de mais de 100\% nos processos envolvendo o INSS de 1994 em diante. (Conselho da Justiça Federal, 2004). Esses dados parecem indicar que, em vez de proteger o cidadão, a União é a parte contrária da qual o cidadão precisa se defender.

c) Tratando, especificamente, dos processos tributários, verifica-se que não há controle no Poder Judiciário que permita saber exatamente quais processos têm efetivamente natureza tributária. Sabe-se que muitos nascem em ações ordinárias ou em mandados de segurança, mas não há identificação dos tributários. Optou-se por considerar, na primeira instância, somente as execuções fiscais para definir o parâmetro de atribuição de despesas de arrecadação. Chama a atenção, porém, o grande número de execuções fiscais federais - mais de $50 \%$ do total - e se percebe que esse fato se repete no âmbito estadual, como informado por Lazzarini (200I), VicePresidente do Tribunal de Justiça do Estado de São Paulo, de que, de 9,7 milhões de ações em tramitação em julho de 200I, havia 5,5 milhões de execuções fiscais, ou $56,7 \%$ do total. Caberia perguntar onde está a causa dessa alta incidência percentual: seria o povo brasileiro refratário ao pagamento de tributos ou estaria sendo produzida uma legislação difícil de ser praticada ou ainda, chegou-se a um nível demasiado elevado de tributação? De qualquer forma, é uma informação que merece estudos, pois 
é uma incidência elevada que onera toda a sociedade com custos que talvez possam ser reduzidos.

d) Com relação aos custos propriamente ditos, apurou-se um valor de $\mathrm{R} \$ 5.5$ bilhões de custos de administração, com uma incidência de 1,35\% sobre a arrecadação e de $0,36 \%$ do PIB. Tomando-se por base a pesquisa de Bertolucci (2003) sobre Custos de Conformidade das empresas de capital aberto, correspondente a $0,75 \%$ do PIB de 2003 que foi de R\$ I.5I 4,9 bilhões, chega-se a R $\$ 11.4$ bilhões. Dessa forma, os custos operacionais tributários do Brasil, sem incluir os custos de conformidade dos contribuintes pessoas físicas, seriam de 1, I 1\% do PIB ou de R $\$ 16.8$ bilhões por ano. Para dar uma idéia do que isso significa, o IBGE informa que, em 2002, o PIB da siderurgia do Brasil correspondeu a $R \$ 16.5$ bilhões. (2004)

e) Comparando a incidência de custos da Administração Tributária do Brasil com a de outros países, verifica-se que são os mais elevados de todos, exceção feita a Portugal que está tão longe dos outros levantamentos que poderia conter algum erro metodológico. Acrescente-se a isso o fato de que não se conhecem os custos dos tributos e contribuições estaduais e municipais, que podem ser percentualmente superiores aos custos da União. Isso porque estudos levados a cabo no Reino Unido por Sandford et al. (1989, p. 134) mostram que o VAT - Value Added Taxation é o tributo de custo operacional mais elevado. Adicionando-se o fato de que muitos Estados ainda não evoluíram tecnicamente e têm baixo nível de sistemas de informação, não seria surpreendente se o custo total fosse mais elevado que o estimado nesta pesquisa.

f) Um aspecto que desperta a atenção durante a pesquisa de campo para apurar os custos das várias atividades ligadas à administração tributária é que não se percebe uma política de transparência sendo adotada, igualmente, por todos os entes do Poder Público. Encontrou-se todo tipo de atitude, desde o interesse e apoio total, até oposição a se obterem as informações necessárias. Entre essas duas posições antagônicas, percebe-se uma gradação de interesse-desinteresse em um ambiente de insegurança quanto à qualidade das informações. Fica claro que é responsabilidade do Poder Público passar a praticar a transparência dos números como, aliás, preceitua a Constituição em seu artigo $5^{\circ}$., inciso XIV e, principalmente, inciso XXXIII, in verbis:

XXXIII - todos têm direito a receber dos órgãos públicos informações de seu interesse particular, ou de interesse coletivo ou geral, que serão prestadas no prazo da lei, sob pena de responsabilidade, ressalvadas aquelas cujo sigilo seja imprescindível à segurança da sociedade e do Estado.

g) Do outro lado do espectro de custos, encontramse Israel, Japão e Noruega, com 0,16\%, 0,26\% e
0,10\%, de incidência de custos de administração sobre a arrecadação, respectivamente.

h) Os Estados Unidos, também, apresentam, nesse sentido, uma incidência bastante reduzida, de $0,44 \%$ da arrecadação. Deve-se notar, porém, que essa informação se refere somente à arrecadação dos tributos federais.

Esta pesquisa indica que o custo de administração de tributos federais, no Brasil, é elevado em relação ao de outros países. Uma proposta de redução desses custos demandaria a análise e discussão das estruturas e vínculos existentes atualmente e isso não está incluído no escopo desta pesquisa. Pelos elementos que surgiram deste trabalho, deverse-ia verificar se a concentração de toda a arrecadação dos tributos federais em um único órgão do Ministério da Fazenda poderia ser benéfica para o aumento da eficiência dessa atividade. Ou seja, se a fusão da SRF, PGFN e INSS, em sua função de administração tributária, poderia aumentar a eficiência e reduzir o custo do Poder Público.

É indispensável, também, que a SRF adote instrumentos estatísticos para aperfeiçoar seu controle, mantendo baixos os seus custos operacionais. Para fazer isso, recomenda-se a utilização da análise discriminante - como, aliás é utilizada pelo IRS nos Estados Unidos - e outros instrumentos como o cluster analysis, para identificar contribuintes com características atípicas a serem fiscalizados. A análise discriminante é definida por Hair (1998, p. 14) como o instrumento matemático aplicável em situações nas quais a amostra total pode ser dividida em agrupamentos baseados em uma variável dependente não métrica. Seu objetivo principal é a possibilidade de identificar diferenças entre os agrupamentos e prever a possibilidade de que uma entidade pertença a um grupo particular. Hair (1998, p. 15 - 16) define também cluster analysis como a técnica analítica para desenvolver sub-grupos significativos de indivíduos ou objetos. Diversamente da análise discriminante, os grupos não são pré-definidos e a técnica é utilizada para identificar os grupos.

Fica evidente, também, que o Poder Público é o grande responsável pela maioria dos processos que sobrecarregam o Poder Judiciário Federal e será necessária uma mudança de atitude por parte dos Poderes Executivo e Legislativo para que os cidadãos não sejam obrigados a se defender de suas ilegalidades. Trata-se, de qualquer modo, de um processo de mudança de longo prazo, cujos reflexos se farão sentir dentro de uma ou mais gerações.

Finalmente, mas não menos importante, é necessário que os sistemas de gestão e de informação contábil e orçamentária sejam aperfeiçoados. Sem sistemas confiáveis não será possível exercer o controle da aplicação de recursos por parte do Poder Público e nem realizar projetos que aumentem a eficiência da Administração Pública. A adoção de uma contabilização baseada nos conceitos da Activity Based Costing seria certamente desejável para se controlar a eficiência do Poder Público na sua alocação de recursos. 


\section{Referências Bibliográficas}

AFONSO, J. R. et al.. Municípios, Arrecadação e Administração Tributária: Quebrando Tabus. Disponível em: <http://www.bndes.gov.br>. Acesso em: 27 maio 2005.

AOKI, T. In: ASSOCIATION FISCALE INTERNATIONALE. Administrative and Compliance Costs of Taxation. Cahiers de Droit Fiscal International. Roterdam, Holanda: Kluwer Law, 1989.

AUSTRALIA. Australian Taxation Office. The Commissioner of Taxation - Annual Report 2002-2003. Disponível em: <http://www.ato.gov. au>. Acesso em: 8 jun. 2004.

BERTOLUCCI, A. V.. Quanto Custa Pagar Tributos. São Paulo: Atlas, 2003.

BERTOLUCCI,A.V.. O Custo de Administração dos Tributos Federais no Brasil: Comparações Internacionais e Propostas para Aperfeiçoamento. Tese. 2005. (Doutorado em Controladoria e Contabilidade) Faculdade de Economia, Administração e Contabilidade da Universidade de São Paulo, São Paulo.

BIRD, R. M.; JANTSCHER, M. C.. Improving Tax Administration in Developing Countries. Washington: International Monetary Fund, 1992.

BNDES. Programa de Modernização da Administração Tributária e Gestão dos Setores Sociais Básicos - PMAT. Disponível em: <http://www. bndes.gov.br/programas/sociais>. Acesso em: 26 maio 2005.

BRASIL. Lei de Responsabilidade Fiscal. São Paulo: Saraiva, 2000.

Ministério da Fazenda. Procuradoria Geral da Fazenda Nacional. Relatório de Gestão 2002. Disponível em: <http://www. pgfn.fazenda.gov.br>. Acesso em: 17 jun. 2003.

Ministério da Fazenda. Procuradoria Geral da Fazenda Nacional. Relatório de Gestão 2003. Disponível em: <http://www. pgfn.fazenda.gov.br>. Acesso em: 18 abr. 2004.

Ministério da Fazenda. Secretaria da Receita Federal. Análise da arrecadação das receitas federais. Disponível em: <http:// www.receita.fazenda.gov.br> Acesso em: 18 abr. 2004.

Ministério da Previdência Social. Anuário Estatístico da Previdência Social 2002. Disponível em: <http://www.inss.gov.br> Acesso em: 6 jun.2004.

. Poder Judiciário. Conselho da Justiça Federal. Movimentação Processual Tribunais Regionais Federais - Período 1993 a 2003.

Disponível em: <http://www.cjf.gov.br/Estatistica/Estatistica.asp >. Acesso em: 05 jun. 2004.

CARVALHO, A. J.. In: ASSOCIATION FISCALE INTERNATIONALE. Administrative and Compliance Costs of Taxation. Cahiers de Droit Fiscal International. Roterdam, Holanda: Kluwer Law, 1989.

CENTRO INTERAMERICANO DE ADMINISTRACIONES TRIBUTARIAS. Formulario para Información del Total de los Ingresos Tributários del Gobierno Central y la Execución Presupuestaria de la Administración Tributária. Panamá: [ca. 2000]

ESTADOS UNIDOS DA AMÉRICA. Internal Revenue Service. Management Discussion and Analysis for the Fiscal Year Ended September 30, 2001. Disponível em: <http://www.irs.gov/pub>. Acesso em: 10 out. 2003.

FEYDEAU, H.; KULBOKAS, F.. In: ASSOCIATION FISCALE INTERNATIONALE. Administrative and Compliance Costs of Taxation. Cahiers de Droit Fiscal International. Roterdam, Holanda: Kluwer Law, 1989.

FREIDKES, N.; GAVISH, M.. In: ASSOCIATION FISCALE INTERNATIONALE. Administrative and Compliance Costs of Taxation. Cahiers de Droit Fiscal International. Roterdam, Holanda: Kluwer Law, 1989.

GREMAUD, J.. In: ASSOCIATION FISCALE INTERNATIONALE. Administrative and Compliance Costs of Taxation. Cahiers de Droit Fiscal International. Roterdam, Holanda: Kluwer Law, 1989.

HAIR, J.F. et al.. MULTIVARIATE DATA ANALYSIS, Upper Saddle River, 5a ed. NJ: Prentice Hall, 1998.

INSTITUTO BRASILEIRO DE GEOGRAFIA E ESTATÍSTICA. Contas Nacionais Trimestrais. Disponível em: <http://www.ibge.gov.br/ home/estatistica/indicadores/pib/cntvol1t04quadro8.shtm>. Acesso em 29 maio 2004.

Contas Nacionais 2000 - 2002 Tabela 2 - Usos de Bens e Serviços pág. 198 - 200. Disponível em: <http://www.ibge.gov.br>.

Acesso em 25 set. 2004.

LAZZARINI, A.. O artigo 20 da Lei de Responsabilidade Fiscal e o Poder Judiciário do Estado de São Paulo. Revista do CRC-SP, São Paulo, v. 137, novembro-dezembro 2001.

NICOLAISSEN, R.H.. In: ASSOCIATION FISCALE INTERNATIONALE. Administrative and Compliance Costs of Taxation. Cahiers de Droit Fiscal International. Roterdam, Holanda: Kluwer Law, 1989.

NORRMAN, B.; MALMER, H.. In: ASSOCIATION FISCALE INTERNATIONALE. Administrative and Compliance Costs of Taxation. Cahiers de Droit Fiscal International. Roterdam, Holanda: Kluwer Law, 1989.

NOVA ZELÂNDIA. Inland Revenue Department. Controller \& Auditor General: Performance of Taxpayer Audit (July 2003). Disponível em: $<$ http://www.ird.govt.nz/aboutir/index.pr.html>. Acesso em 20 jun. 2004.

REINO UNIDO. Inland Revenue Service. Inland Revenue Annual Report. Disponível em: <http://www.inlandrevenue.gov.uk/pdfs/ report2002.pdf>. Acesso em 10. jun. 2004.

SANDFORD, C.; GODWIN, M.; HARDWICK, P.. Administrative and Compliance Costs of Taxation. Bath: Fiscal Publications, 1989. 
In: ASSOCIATION FISCALE INTERNATIONALE. Administrative and Compliance Costs of Taxation. Cahiers de Droit Fiscal International. Roterdam, Holanda: Kluwer Law, 1989.

VAILLANCOURT, F.; REID, R.J.. In: ASSOCIATION FISCALE INTERNATIONALE. Administrative and Compliance Costs of Taxation. Cahiers de Droit Fiscal International. Roterdam, Holanda: Kluwer Law, 1989.

WORLD BANK. 2005 World Development Indicators. Disponível em: <http://www.worldbank.org/data/>. Acesso em 15 maio 2005.

\section{NOTA - Endereço dos autores}

Universidade de São Paulo

Faculdade de Economia, Administração e Contabilidade Departamento de Contabilidade e Atuária
Av. Prof. Luciano Gualberto, 908 - prédio 3 -

Cidade Universitária

São Paulo - SP

05.508-900 